\title{
Relationship between Cardiovascular Risk Factors and Adipokines in Adolescents
}

\author{
Daniela A. Rubin Robert G. McMurray Anthony C. Hackney Joanne S. Harrell \\ Department of Exercise and Sport Science, University of North Carolina at Chapel Hill, Chapel Hill, N.C., USA
}

\section{Key Words}

Blood pressure $\cdot$ Cytokines $\cdot$ Lipids · Obesity $\cdot$ Adolescents

\begin{abstract}
This study evaluated the associations of adipokines with cardiovascular risk factors. Subjects/Methods: 60 normal weight (BMI $\leq 75$ th percentile) and 60 overweight (BMI $\geq 95$ th percentile) adolescents aged 10-14 years. Resting systolic and diastolic blood pressures (SBP, DBP) and waist circumference were obtained in duplicate. Circulating adiponectin, resistin, tumor necrosis factor- $\alpha$ (TNF- $\alpha$ ), interleukin-6 (IL-6), total cholesterol (TC), high-density lipoprotein $(\mathrm{HDL})$, and triglycerides (TG) were measured from fasting plasma samples. Results: Simple correlations showed that SBP was significantly related $(p<0.05)$ to adiponectin $(r=$ $-0.185)$, resistin $(r=0.207)$, and IL-6 $(r=0.238)$; HDL was significantly related to adiponectin $(r=0.398)$ and TNF- $\alpha(r=$ $-0.227)$. TG was only related to adiponectin $(r=-0.292, p<$ 0.05 ). Multiple regression models controlling for puberty and ethnicity indicated that adiponectin $\left(R^{2}=0.152, p<\right.$ $0.05)$, resistin $\left(R^{2}=0.152, p<0.05\right)$, and IL-6 $\left(R^{2}=0.170, p<\right.$ 0.05 ) were associated with SBP. The association between adiponectin and HDL was stronger in normal weight versus overweight adolescents $\left(R^{2}=0.336, p<0.05\right)$. None of the other models showed differences in the associations by weight status. Conclusions: In adolescents, SBP but not DBP
\end{abstract}

was associated with most adipokines. HDL, but not TC, was also associated with some adipokines. TG were only associated with adiponectin. Associations were mostly related to adiposity.

Copyright $\odot 2011$ S. Karger AG, Basel

\section{Introduction}

In children and adults, the association between obesity and the presence of cardiovascular disease risk factors and insulin resistance is well established [1-4]. However, the mechanisms relating adiposity to the atherosclerotic process are still under study [5]. One of several proposed hypotheses is that adipose tissue acts as a secretory gland releasing hormones and adipokines with proor anti-inflammatory activity $[5,6]$. These adipokines in turn affect either glucose or fat transport/utilization, triglycerides (TG) production, or endothelial function in a negative or positive way $[5,7-10]$.

Tumor necrosis factor- $\alpha$ (TNF- $\alpha$ ), adiponectin, and resistin have been previously associated with insulin resistance and obesity in youth [11], as well as other cardiovascular disease risk factors such as blood pressure (BP) [12-14]. Elevated interleukin-6 (IL-6) concentrations have been associated with cardiovascular disease in adults [15] and higher IL- 6 concentrations appear to be

\section{KARGER}

(C) 2011 S. Karger AG, Basel

Fax +41613061234

E-Mail karger@karger.ch

www.karger.com
Accessible online at: www.karger.com/hrp
Daniela A. Rubin, $\mathrm{PhD}$

Department of Kinesiology, KHS 138

California State University Fullerton

800 N. State College Blvd., Fullerton, CA 92834-3599 (USA)

Tel. +1 657278 4704, E-Mail drubin@ fullerton.edu 
present in youth with the metabolic syndrome [3]. Data is also present suggesting that some of these associations are dependent on adiposity levels $[11,14]$. However, no study has demonstrated associations of resistin with $\mathrm{BP}$ or lipids in youth [16].

Although several studies have been conducted to date on this topic, most of the previous studies in children focused on a particular adipokine, mostly adiponectin. Moreover, given the interrelationship between insulin resistance and cardiovascular disease $[1,5,7]$, it would be expected that adipokines related to insulin resistance are associated with other cardiovascular risk factors. The purpose of this study is twofold: first to evaluate the associations between different adipokines and BP and blood lipids, and second to evaluate if these associations are attenuated by overall or abdominal adiposity or dependent on weight status. We hypothesized that TNF- $\alpha$, IL-6, and resistin would be positively associated with systolic blood pressure (SBP), TG, total cholesterol (TC), and negatively associated with high-density lipoprotein (HDL). In contrast, adiponectin would be negatively associated with SBP, TG, TC, and positively associated with HDL. Furthermore, these relationships would be exacerbated in overweight adolescents and attenuated by adiposity.

\section{Subjects and Methods}

\section{Subjects}

Data from 120 adolescents (60 girls and 60 boys), aged 10-14 years who participated in the Cardiovascular Health in Children and Youth (CHIC III) Study between 2000 and 2003, were utilized for this retrospective study. The CHIC studies have been multi-cohort studies, focused on cardiovascular risk factors in school-aged youth $[17,18]$. All subjects signed an assent and their parents or guardians signed an informed consent approved by the institutional review board of the institution. Potential subjects for this analysis had to be in pubertal developmental stages 2-4 (mid-puberty) and have normal glucose concentrations (fasting glucose $<5.6 \mathrm{mmol} / \mathrm{l}$ ). All subjects meeting the prescribed criteria were included in the subject pool. Body mass index (BMI) percentiles by age and sex were used to classify youth into obese and normal weight categories [19]. BMI percentile was chosen because it is the standard clinical criteria in the USA for determination of weight status [19]. The 75th and 95th percentile thresholds were chosen to maximize differences in adiposity between the normal weight and overweight groups. From the subject pool, a subset was identified which included those with a BMI $\leq 75$ th percentile (normal weight) and those with BMI $\geq 95$ th percentile (overweight). From this subset 60 normal weight and 60 overweight subjects were randomly selected based on their sex using the select random cases procedure of the Statistical Package for Social Sciences for Windows version 9.0 (SPSS Inc., Chi- cago, Ill., USA). 60 subjects per group were sufficient to detect group differences of $0.4 \mathrm{ng} / \mathrm{ml}$ for TNF- $\alpha, 0.6 \mathrm{ng} / \mathrm{ml}$ for IL- $6,2.1$ $\mathrm{ng} / \mathrm{ml}$ for resistin and $1.6 \mathrm{mg} / \mathrm{ml}$ for adiponectin, with an $\alpha=$ $0.05, \beta=0.2$ and a power of $80 \%$.

Anthropometric, Pubertal Status and BP Measurements

Measurements took place in the school setting within 3 days of blood sampling. The subjects were dressed in shorts and Tshirts without shoes. Height was measured to the nearest $0.1 \mathrm{~cm}$ using a stadiometer (Perspective Enterprises, Kalamazoo, Mich., USA) and body mass was obtained in kilograms to the nearest 0.1 $\mathrm{kg}$ using a Scale-Tronix electronic scale (model 5602; Scale-Tronix, Carol Stream, Ill., USA). BMI was computed using body mass in kilograms divided by height in meters squared (BMI = $\mathrm{kg} / \mathrm{m}^{2}$ ) and used as an indicator of overall adiposity. Waist circumference was measured in duplicate to the nearest $0.1 \mathrm{~cm}$ using a tape with tensiometer (Gulick Tape; Country Technologies Inc., Gays Mill, Wisc., USA) and was used as an indicator of abdominal adiposity. All measurements were obtained following procedures described by the National Health and Nutrition Examination Survey [20]. Puberty was determined using a validated self-completed questionnaire that assessed puberty based on growth spurt in height, pubic hair development, skin changes in both boys and girls, facial hair growth and voice change in boys only, and breast development and menarche in girls [21]. Ethnicity was self-reported.

After the anthropometric measures were obtained the subjects sat for 5 min before BP was measured using a random-zero mercury sphygmomanometer and appropriately sized cuff (Baum Inc., Copiague, N.Y., USA). BP readings were obtained in duplicate in the right arm following American Heart Association procedures. If the pressure readings differed by $\geq 10 \mathrm{~mm} \mathrm{Hg}$, a third reading was taken and the three readings averaged.

\section{Blood Sampling and Analyses}

Blood samples were obtained after an overnight fast, between 7 and 9 a.m., at the school, using sterile venipuncture technique. Fasting compliance was verbally verified by on-site research assistants. Blood samples were collected in tubes containing EDTA and immediately centrifuged to obtain plasma. Plasma was aliquoted, maintained in dry ice and transported to the laboratory where it was kept frozen at $-80^{\circ} \mathrm{C}$ until analyzed. Concentrations of TC, HDL cholesterol and TG were tested on fasting plasma samples using automated coupled-enzymatic procedures and a Hitachi 911 analyzer (Boehringer-Mannheim Corp.) by a CLIAapproved clinical laboratory.

Concentrations of plasma of the adipokines resistin, TNF- $\alpha$, IL-6, and adiponectin were measured using standard enzyme immunoassay procedures (Linco Research Inc., St. Charles, Mo., and R\&D Systems, Minneapolis, Minn., USA). The resistin assay had a sensitivity of $0.5 \mathrm{ng} / \mathrm{ml}$ with intra- and inter-assay coefficients of variation of $<10$ and $11.2 \%$, respectively. The adiponectin assay had a limit of sensitivity of $0.78 \mathrm{ng} / \mathrm{ml}$ with intra- and inter-assay coefficients of variation of $<10$ and $11.6 \%$, respectively. The TNF$\alpha$ kit had a sensitivity of $0.5 \mathrm{pg} / \mathrm{ml}$ while the IL- 6 kit had a sensitivity of $0.2 \mathrm{pg} / \mathrm{ml}$. The intra-assay coefficient of variation for TNF- $\alpha$ and IL- 6 was $<10 \%$. The inter-assay coefficient of variation for TNF- $\alpha$ was $12.2 \%$ and for IL- 6 was $18.2 \%$. 
Table 1. Anthropometric and metabolic characteristics of subjects by weight status groups: mean \pm SD (minimum-maximum)

\begin{tabular}{lcc}
\hline & Normal weight $(\mathrm{n}=60)$ & Overweight $(\mathrm{n}=60)$ \\
\hline Physical & & \\
Female/male & $30 / 30$ & $30 / 30$ \\
Age, years & $12.0 \pm 1.0(10-14)$ & $12.0 \pm 1.0(11-14)$ \\
Puberty (stages 1-5) & $2.9 \pm 0.7(2-4)$ & $3.2 \pm 0.7^{*}(2-4)$ \\
Stature, cm & $152.1 \pm 7.6(135.4-170.3)$ & $159.8 \pm 7.9^{*}(144.7-186)$ \\
Body mass, kg & $40.4 \pm 5.9(26.7-56.6)$ & $76.3 \pm 15.2^{*}(52.4-123)$ \\
BMI & $17.4 \pm 1.4(13.6-20.1)$ & $29.7 \pm 5.0^{*}(23.7-46.4)$ \\
Waist, cm & $61.7 \pm 5.3(52.3-80.2)$ & $90.0 \pm 10.5^{*}(70.1-118.8)$ \\
\hline CVR risk factors & & \\
SBP, mm Hg & $103 \pm 10(85-120)$ & $113 \pm 11^{*}(93-143)$ \\
DBP, mm Hg & $65 \pm 11(36-89)$ & $66 \pm 10(43-99)$ \\
TC, mg/dl & $154.6 \pm 25.3(102-258)$ & $40.6 \pm 8.3^{*}(24-58)$ \\
HDL, mg/dl & $52.5 \pm 10.7(34-87)$ & $86.7 \pm 39.1^{*}(27-189)$ \\
TG, mg/dl & $61.9 \pm 25.8(25-155)$ & \\
\hline Adipokines & & $7.6 \pm 3.4^{*}(2.9-19.4)$ \\
Adiponectin, $\mu$ g/ml & $11.3 \pm 6.0(4.4-41.3)$ \\
Resistin, ng/ml & $12.5 \pm 5.0(4.4-30.4)$ & $1.9 \pm 1.4^{*}(0.3-7.2)$ \\
TNF- $\alpha, \mathrm{pg} / \mathrm{ml}$ & $10.2 \pm 4.0(3.7-22.3)$ & $1.8 \pm 2.0(0.2-9.6)$ \\
IL-6, pg/ml & $1.4 \pm 0.7(0.2-3.8)$ &
\end{tabular}

${ }^{*} \mathrm{p}<0.05$ for weight status groups (normal weight vs. overweight).

\section{Statistical Analysis}

For descriptive purposes, mean and standard deviations were computed for all variables by weight groups. Since the adipokines and lipid concentrations were not normally distributed, their values were transformed using the natural log. To determine the associations between SBP, lipids and each adipokine, analyses were conducted in three steps. First, we computed bivariate correlations between BP, lipids, and all adipokines. Second, for those associations that were statistically significant we tested several multiple regression models. The first model included the risk factor (SBP, TC, HDL, or TG) and one adipokine controlling for ethnicity (African-American, Caucasian and other), sex, age or puberty. Only control variables that were significantly associated with the dependent variable in this first model were kept in subsequent models. The second model was computed to evaluate if the association between the risk factor and the adipokine was attenuated by abdominal adiposity (waist circumference). The third model was computed to evaluate if the association was present depending on the weight status of the adolescents and included an interaction term between the adipokines and weight status. Weight status was based on the BMI percentile ( $\leq 75$ th and $\geq 95$ th percentile) indicating normal weight or obesity. Interaction terms not statistically significant were excluded from the models presented. Statistical significance was held at $\mathrm{p}<0.05$. Analyses were conducted using SPSS for Windows version 9.0.

Adipokines and Cardiometabolic Factors in Adolescents

\section{Results}

\section{Subjects' Characteristics}

The subjects' characteristics are presented in table 1 by weight groups. Racial distribution was 57\% AfricanAmerican, 37\% Caucasian, and 6\% other races including Native American, Asian and other. 29 participants were in pubertal stage 2, 53 were in pubertal stage 3 , and 38 were in pubertal stage 4 . The overweight group was taller and slightly advanced in pubertal status than the normal weight group. In addition, some cardiovascular risk factors and adipokine concentrations were significantly $(\mathrm{p}<0.05)$ different between normal and overweight adolescents.

Bivariate Correlations in the Whole Cohort

SBP was significantly $(\mathrm{p}<0.05)$ related to adiponectin $(r=-0.185)$, resistin $(r=0.207)$, and IL-6 $(r=0.238)$. Diastolic blood pressure (DBP) was not related to any adipokine $(\mathrm{p}>0.05)$. HDL was significantly $(\mathrm{p}<0.05)$ associated with adiponectin $(r=0.398)$ and TNF- $\alpha(r=-0.227)$, while TG were only associated with adiponectin ( $\mathrm{r}=$ $-0.292 ; p<0.05)$. No other significant associations were obtained. 
Table 2A. Multivariate regression models for the relationships between SBP and adipokines controlling for ethnicity and puberty

\begin{tabular}{lcccc}
\hline $\begin{array}{l}\text { Independent } \\
\text { variable }\end{array}$ & $\begin{array}{l}\beta \text {-Coef- } \\
\text { ficient }\end{array}$ & $\mathrm{p}$ & Model $\mathrm{R}^{2}$ & $\mathrm{p}$ \\
\hline Adiponectin & -0.195 & 0.028 & 0.152 & 0.001 \\
\hline Adiponectin & 0.038 & 0.677 & & \\
Waist & 0.463 & 0.000 & 0.308 & 0.000 \\
\hline Adiponectin & 0.003 & 0.975 & & \\
Weight status & 0.382 & 0.000 & 0.253 & 0.000 \\
\hline Resistin & 0.147 & 0.110 & 0.152 & 0.002 \\
\hline Resistin & 0.079 & 0.343 & & \\
Waist & 0.426 & 0.000 & 0.308 & 0.000 \\
\hline Resistin & 0.107 & 0.214 & & \\
Weight status & 0.361 & 0.000 & 0.258 & 0.000 \\
\hline IL-6 & 0.246 & 0.008 & 0.170 & 0.000 \\
\hline IL-6 & 0.134 & 0.103 & & \\
Waist & 0.420 & 0.000 & 0.330 & 0.000 \\
\hline IL-6 & 0.177 & 0.035 & & \\
Weight status & 0.363 & 0.000 & 0.289 & 0.000 \\
\hline
\end{tabular}

Significant models presented.

Weight status coding: normal $=0$ (BMI <75th percentile); overweight $=1$ (BMI $>95$ th percentile).

All cytokines were logarithmically transformed.

\section{Multiple Regression Analyses}

Regression analyses were conducted only for SBP, HDL, TG and the adipokines that were significantly related to them in the bivariate analyses. For each parameter, several separate regression models were tested; initially all control variables were included in the first model but only significant ones were kept in subsequent models. All regression models for SBP included puberty and ethnicity as control variables. HDL and TG models did not include control variables. The standardized $\beta$ coefficients \pm SE are presented for each adipokine as well as the total $\mathrm{R}^{2} \pm \mathrm{SE}$ for the regression model. For $\mathrm{SBP}$, the models containing adiponectin, resistin and IL- 6 were significant (table 2A). Waist circumference attenuated all associations $(\mathrm{p}<0.001)$ and so did weight status $(\mathrm{p}<0.001)$. HDL was significantly associated with adiponectin, presenting a significant interaction term between adiponectin and weight status $(\mathrm{p}=0.033)$. HDL was negatively associated with TNF- $\alpha(\mathrm{p}=0.021)$, but the association became attenuated when waist circumference or weight status were included in the model ( $\mathrm{p}=$ 0.087 and $p=0.229$, respectively). TG were also associated with adiponectin, but the weight status interaction
Table 2B. Multivariate regression models for the relationships between HDL and TG, with adiponectin, and TNF- $\alpha$

\begin{tabular}{|c|c|}
\hline Independent variable & $\begin{array}{l}\beta \text {-Coef- } p \\
\text { ficient }\end{array}$ \\
\hline
\end{tabular}

\begin{tabular}{lrrrr}
\hline HDL models & & & & \\
Adiponectin & 0.390 & 0.000 & 0.152 & 0.000 \\
\hline Adiponectin & 0.146 & 0.097 & & \\
Waist & -0.489 & 0.000 & 0.332 & 0.000 \\
\hline Adiponectin & 0.339 & 0.009 & & \\
Weight status & 0.434 & 0.312 & & \\
Adiponectin and weight status & -0.830 & 0.033 & 0.336 & 0.000 \\
\hline TNF- $\alpha$ & -0.216 & 0.021 & 0.046 & 0.021 \\
\hline TNF- $\alpha$ & -0.136 & 0.087 & & \\
Waist & -0.535 & 0.000 & 0.327 & 0.000 \\
\hline TNF- $\alpha$ & -0.099 & 0.229 & & \\
Weight status & -0.511 & 0.000 & 0.294 & 0.000 \\
\hline
\end{tabular}

\section{Triglyceride model}

\begin{tabular}{lrrrr} 
Adiponectin & -0.350 & 0.000 & 0.176 & 0.000 \\
\hline Adiponectin & -0.142 & 0.162 & & \\
Weight status & 0.282 & 0.006 & 0.142 & 0.000 \\
\hline Adiponectin & -0.119 & 0.224 & & \\
Waist & 0.346 & 0.001 & 0.175 & 0.000 \\
& & & &
\end{tabular}

was not significant $(\mathrm{p}>0.05)$. Both waist circumference and weight status attenuated this last association (table 2B).

\section{Discussion}

We evaluated the associations between BP and lipids and 4 adipokines. SBP was associated with adiponectin, resistin and IL-6. HDL was related to adiponectin and TNF- $\alpha$, while TG were only associated with adiponectin. DBP and TC were not significantly associated with any adipokine in the participating youth. The associations obtained in our study were significant but not very strong. Since stronger associations have been reported in adults $[15,22-24]$, the weak associations may be simply due to the fact that adolescents have not had sufficient time to fully develop the relationships.

Some research has shown that increased adiponectin is associated with lower SBPs $[13,25]$. In vitro, adiponectin reduces monocyte adhesion in endothelial cells, preventing the development of lesions in the endothelium [10]. It also prevents increases in the intima media thick- 
ness modulating smooth muscle proliferation [26]. Therefore, the negative associations between SBP and this adipokine are not surprising. The positive associations between SBP and resistin and IL- 6 are novel findings in youth. Gilardini et al. [27] failed to demonstrate an association between ambulatory SBP and IL- 6 in obese young children. However, the positive association found in the present study appears reasonable since studies in youth with obesity of varying degrees and metabolic syndrome have shown elevations of IL- 6 concentrations compared to normal weight youth [3].

Moon et al. [14] showed a positive association of TNF$\alpha$ with BP in older obese adolescents, but we did not. TNF- $\alpha$ appears to suppress the release of nitric oxide (a vasodilator), therefore increasing total peripheral resistance and BP [28]. Our sample included both normal weight and overweight younger adolescents. Perhaps in obese youth this association manifests itself with increasing age.

The overweight adolescents had higher circulating concentrations of TG and low levels of HDL than the normal weight adolescents. Concomitantly, we found a positive association between HDL and adiponectin and a negative association between TG and adiponectin. These results support previous findings by Huang et al. [29] and Bacha et al. [25]. Interestingly, the association between adiponectin and HDL was stronger in normal weight adolescents, perhaps because these adolescents had higher HDL concentrations as well as higher adiponectin concentrations. The negative association between adiponectin and TG could potentially be related to the fact that adiponectin has been shown to inhibit TG production by the liver [8].

Van Gaal et al. [5] suggested that visceral fat production of IL- 6 and TNF- $\alpha$, as part of the inflammatory process, affects liver production of lipids. TNF- $\alpha$ is associated with increased TG production, and a decrease in lipoprotein lipase [30]. IL-6 in turn stimulates the release of very-low-density lipoproteins which can become oxidized to low-density lipoprotein. Moon et al. [14] showed a positive association between TNF- $\alpha$ and TG in obese adolescents and we showed a negative association with HDL further expanding on the relationship between TNF- $\alpha$ and dyslipidemia.

To our knowledge, no other studies have shown associations between lipids and resistin in youth. However, in adults, resistin was positively associated with TG and negatively with HDL concentrations [24]. In mice, resistin has been related to increased hepatic lipogenesis and very-low-density lipoproteins export [31]. Because the average values of lipids are lower in youth than adults [32], it is possible that the relationship between resistin and lipids becomes evident at older ages when dyslipidemia is more prevalent. The relationship between lipids and IL- 6 , in particular between IL- 6 and TG, has only been recently shown in obese adolescents but not in normal weight or overweight adolescents [33]. Interestingly, previous studies in adults did not show such an association $[22,23]$. Probably since our study included normal weight and obese adolescents, we did not detect this association either.

We and others have previously demonstrated small ( $\sim 20 \%$ ) differences in these adipokine concentrations between overweight and normal weight youth [3, 14, 29, 34]. Therefore, as our data suggest, the associations between these adipokines and cardiovascular risk factors in youth are dependent on adiposity, as associations were attenuated when including adiposity surrogates in the regression models. We also know that BP is related to stature as well as adiposity and our overweight group was taller than our normal weight group (table 1). Our data, not reported here, suggests that the relationship between BP and weight is stronger than the relationship between $\mathrm{BP}$ and height. Furthermore, there is strong collinearity between height and weight; thus we chose not to adjust our $\mathrm{BP}$ analysis for height.

The adipose tissue is one source of all these adipokines $[6,28,35,36]$ and adiponectin is produced solely by the adipocyte. In contrast, TNF- $\alpha$, IL- 6 and resistin are also produced by the muscle and immune system cells $[6,28$, 35]. Since the prevalence of cardiovascular risk factors is higher with increased adiposity, the associations between this particular adipokine and risk factors is perhaps more consistent $[11,25,29]$. A potential hypothesis is that adipokines explain part of the inter-individual variability of BP or blood lipids not already explained by adiposity (BMI or waist circumference). Although our data does not allow us to test this hypothesis, we can suggest that in youth any influence of the adipokines is, in most cases, dependent on adiposity.

This study was conducted in previously collected blood samples. There was no control in the day-to-day variation in adipokine concentrations, however they were within ranges of previously published concentrations in youth $[3,12,14,25,29]$. The even sample size of normal weight and overweight subjects allowed inferences on the role of weight status in the studied associations. However, this sample characteristic may have limited the results with respect to the cardiovascular risk factors, as their prevalence increases with increased adiposity. 


\section{Conclusion}

The understanding of the roles of these adipokines is still a work in progress. We extended the knowledge by showing associations not only between adiponectin and BP or lipids, but also resistin, TNF- $\alpha$ and IL-6. SBP was related to most of the adipokines evaluated in this study. Higher SBP was associated with higher resistin and IL-6 concentrations and lower adiponectin concentrations. Higher HDL was associated with lower TNF- $\alpha$ and higher adiponectin concentrations while lower TG were associated with higher adiponectin concentrations. Neither
DBP nor TC were related to any of the adipokines. The available evidence suggests that increased adiposity mediates these associations between adipokines and cardiovascular risk factors during adolescence as most associations were attenuated by waist circumference or weight status.

\section{Acknowledgements}

This work was supported by the National Institutes of Health (NIH-NINRR01837) and the University of North Carolina at Chapel Hill (Graduate Student Trust Fund and the Department of Exercise and Sport Science).

\section{References}

1 Reaven GM: Banting Lecture 1988. Role of insulin resistance in human disease. Diabetes 1988;37:1595-1607.

-2 Sinaiko AR, Steinberger J, Moran A, Hong CP, Prineas RJ, Jacobs DR Jr: Influence of insulin resistance and body mass index at age 13 on systolic blood pressure, triglycerides, and high-density lipoprotein cholesterol at age 19. Hypertension 2006;48:730-736

$\checkmark 3$ Weiss R, Dziura J, Burgert TS, Tamborlane WV, Taksali SE, Yeckel CW, Allen K, Lopes M, Savoye M, Morrison J, Sherwin RS, Caprio S: Obesity and the metabolic syndrome in children and adolescents. N Engl J Med 2004;350:2362-2374.

4 Williams DE, Cadwell BL, Cheng YJ, Cowie CC, Gregg EW, Geiss LS, Engelgau MM, Narayan KM, Imperatore G: Prevalence of impaired fasting glucose and its relationship with cardiovascular disease risk factors in US adolescents, 1999-2000. Pediatrics 2005; 116:1122-1126.

5 Van Gaal LF, Mertens IL, Block CD: Mechanisms linking obesity with cardiovascular disease. Nature 2006;444:875-880.

$\checkmark 6$ Kershaw EE, Flier JS: Adipose tissue as an endocrine organ. J Clin Endocrinol Metab 2004;89:2548-2556.

-7 Hajer GR, van Haeften TW, Visseren FL: Adipose tissue dysfunction in obesity, diabetes, and vascular diseases. Eur Heart J 2008;29: 2959-2971.

8 Yamauchi T, Kamon J, Minokoshi Y, Ito Y, Waki H, Uchida S, Yamashita S, Noda M, Kita S, Ueki K, Eto K, Akanuma Y, Froguel P, Foufelle F, Ferre P, Carling D, Kimura S, Nagai R, Kahn BB, Kadowaki T: Adiponectin stimulates glucose utilization and fatty-acid oxidation by activating AMP-activated protein kinase. Nat Med 2002;8:1288-1295.

-9 Steppan CM, Bailey ST, Bhat S, Brown EJ, Banerjee RR, Wright CM, Patel HR, Ahima RS, Lazar MA: The hormone resistin links obesity to diabetes. Nature 2001;409:307-312.
10 Ouchi N, Kihara S, Arita Y, Maeda K, Kuriyama H, Okamoto Y, Hotta K, Nishida M Takahashi M, Nakamura T, Yamashita S, Funahashi T, Matsuzawa Y: Novel modulator for endothelial adhesion molecules: adipocyte-derived plasma protein adiponectin. Circulation 1999;100:2473-2476.

-11 Rubin DA, McMurray RG, Harrell JS, Hackney AC, Thorpe DE, Haqq AM: The association between insulin resistance and cytokines in adolescents: the role of weight status and exercise. Metabolism 2008;57:683-690.

12 Chu NF, Shen MH, Wu DM, Lai CJ: Relationship between plasma adiponectin levels and metabolic risk profiles in Taiwanese children. Obes Res 2005;13:2014-2020.

13 Huang KC, Chen CL, Chuang LM, Ho SR, Tai TY, Yang WS: Plasma adiponectin levels and blood pressures in nondiabetic adolescent females. J Clin Endocrinol Metab 2003; 88:4130-4134

14 Moon YS, Kim DH, Song DK: Serum tumor necrosis factor- $\alpha$ levels and components of the metabolic syndrome in obese adolescents. Metabolism 2004;53:863-867.

15 Barbieri M, Ferrucci L, Corsi AM, Macchi C Lauretani F, Bonafè M, Olivieri F, Giovagnetti S, Franceschi C, Paolisso G: Is chronic inflammation a determinant of blood pressure in the elderly? Am J Hypertens 2003;16 537-543.

-16 Gerber M, Boettner A, Seidel B, Lammert A, Bar J, Schuster E, Thiery J, Kiess W, Kratzsch $\mathrm{J}$ : Serum resistin levels of obese and lean children and adolescents: biochemical analysis and clinical relevance. J Clin Endocrinol Metab 2005;90:4503-4509.

-17 Harrell JS, McMurray RG, Gansky SA, Bangdiwala SI, Bradley CB: A public health versus a risk-based intervention to improve cardiovascular health in elementary school children: the Cardiovascular Health in Children Study. Am J Public Health 1999;89:15291535
18 McMurray R, Harrell J, Bangdiwala S: A school-based intervention can reduce body fat and blood pressure in young adolescents. J Adolesc Health 2002:31:125-132.

19 Centers for Disease Control and Prevention National Centers for Health Statistics. CDC Growth Charts: United States, May 30, 2000 (http://www.cdc.gov/growthcharts).

20 United States Department of Human and Health Services. NHANES III Reference Manuals and Reports; in National Center for Health Statistics. Hyattsville, MD, CDC Prevention, 1996.

21 Petersen AC, Crockett L, Richards M: A selfreport measure of pubertal status: reliability, validity, and initial norms. J Youth Adolesc; 1988;17:117-133.

22 Chan DC, Watts GF, Ng TW, Uchida Y, Sakai N, Yamashita S, Barrett P: Adiponectin and other adipocytokines as predictors of markers of triglyceride-rich lipoprotein metabolism. Clin Chem 2005;51:578-585.

23 Li JJ, Li YS, Chu JM, Zhang CY, Wang Y, Huang Y, Chen J, Yuang JQ, Huang Y: Changes of plasma inflammatory markers after withdrawal of statin therapy in patients with hyperlipidemia. Clin Chem Acta 2006; 366:269-273.

24 Norata G, Ongari M, Garlaschelli K, Raselli S, Grigore L, Catapano A: Plasma resistin levels correlate with determinants of the metabolic syndrome. Eur J Endocrinol 2007; 156:279-284.

25 Bacha F, Saad R, Gungor N, Arslanian SA: Adiponectin in youth: relationship to visceral adiposity, insulin sensitivity, and $\beta$-cell function. Diabetes Care 2004;27:547-552.

26 Kubota N, Terauchi Y, Yamauchi T, Kubota T, Moroi M, Matsui J, Eto K, Yamashita T, Kamon J, Satoh H, Yano W, Froguel P, Nagai R, Kimura S, Kadowaki T, Noda T: Disruption of adiponectin causes insulin resistance and neointimal formation. J Biol Chem 2002; 277:25863-25866. 
-27 Gilardini L, Parati G, Sartorio A, Mazzilli G, Pontiggia B, Invitti C: Sympathoadrenergic and metabolic factors are involved in ambulatory blood pressure rise in childhood obesity. J Hum Hypertens 2008;22:75-82.

28 De Ferranti S, Mozaffarian D: The perfect storm: obesity, adipocyte dysfunction, and metabolic consequences. Clin Chem 2008; 54:945-955.

- 29 Huang KC, Lue BH, Yen RF, Shen CG, Ho SR, Tai TY, Yang WS: Plasma adiponectin levels and metabolic factors in nondiabetic adolescents. Obes Res 2004;12:119-124

-30 Chan DC, Barrett PH, Watts GF: Recent studies of lipoprotein kinetics in the metabolic syndrome and related disorders. Curr Opin Lipidol 2006;17:28-36.
Singhai NS, Patel RT, Qi Y, Lee Y-S, Ahima $\mathrm{R}$ : Loss of resistin ameliorates hyperlipidemia and hepatic steatosis in leptin-deficient mice. Am J Physiol Endocrinol Metab 2008; 295:E331-E338.

32 Belcher JD, Ellison RC, Shepard WE, Bigelow C, Webber LS, Wilmore JH, Parcel GS, Zucker DM, Luepker RV: Lipid and lipoprotein distributions in children by ethnic group, gender, and geographic locationpreliminary findings of the Child and Adolescent Trial for Cardiovascular Health (CATCH). Prev Med 1993;22:143-153.

33 Carvalho GQ, Pereira PF, Serrano HM, do Carmo Castro Franceschini S, Oliveira de Paula S, Priore SE, do Carmo Gouveia Peluzio M: Peripheral expression of inflammatory markers in overweight female adolescents and eutrophic female adolescents with a high percentage of body fat. Appl Physiol Nutr Metab 2010;35:464-70.
34 Rubin DA, McMurray RG, Harrell JS, Hackney AC, Haqq AM: Do surrogate markers for adiposity relate to cytokines in adolescents? J Investig Med 2008;56:786-792.

35 Petersen AM, Pedersen BK: The anti-inflammatory effect of exercise. J Appl Physiol 2005;98:1154-1162.

36 Trayhurn P, Wood IS: Signaling role of adipose tissue: adipokines and inflammation in obesity. Biochem Soc Trans 2005;33:10781081. 